\title{
Development and Application of Horticultural Kit for Children's Horticulture Education
}

\author{
Hye Ran Kwack \\ Professor, Department of Science \& Technological Education for Life, Seoul National University of Education, Seoul 06639, Republic of Korea
}

\section{ABSTRACT}

Background and objective: For effective horticultural education, it is required to develop kits for practice. In this study, we developed a horticultural kit for germination that introduces storytelling, characterization, and assembly, and investigated the educational effects of using it to study its educational differentiation and usefulness.

Methods: First, we developed a seed germination kit for learning. It consists of three components: the kit main frame for hydroponics, the activity sheet for storytelling, and the instruction manual. It is made into an acrylic assembly in consideration of the ease of delivery for contactless learning. Second, we developed two programs, each using a germination kit for horticultural education (experimental group) and a general germination kit program (control group). At this time, the class consists of pre-questionnaire, the 1st and 2 nd classes, observation log writing (total six times for two weeks), the 3rd class, and post-questionnaire. The experimental group and control group were separately executed. Third, the application results were compared and analyzed before and after class. As a quantification questionnaire, the effects before and after class were compared through $\mathrm{t}$-test with a questionnaire on program satisfaction and attitude change toward plants. The quantitative results were analyzed through observation activity sheets and effects before and after the class were analyzed through $\mathrm{t}$-test with quantification and language coding.

Results: The effect of horticulture education using the developed kit was estimated by a quantification questionnaire. Both the program satisfaction and the change in attitude toward plants showed high in the experimental group, and this difference was statistically significant $(p<.05)$. As a result of analyzing the observation paper with a qualitative questionnaire, various cognitive and affective expressions appeared in the experimental group as well as the contents of the observation paper. The number of syllables and various qualitative expressions appeared, and these differences were also statistically significant $(p<.05)$.

Conclusion: Compared to general germination activities, it was found that the germination activities using storytellingbased horticultural kits would be effective for contactless classes in the post-COVID-19 era and in increasing the educational effect of horticultural activities.

Keywords: germination kit for education, characterization, storytelling, contactless class, satisfaction with plants, interest in plants

\section{Introduction}

Until now, it has been revealed through many previous studies that plant education can give students various positive experiences. However, such a horticultural education environment is not well provided at school sites, and it is considered to have many difficulties in teaching. This is usually attributed to the lack of practice environment, lack of practical experience, and lack of training activities related to teachers' practice (Park, 2005). In particular, there are many schools that lack a practical environment in downtown areas, so it is necessary to prepare an alter-

This work was supported by the 2021 Research Fund of Seoul National University of Education.

Received: November 23, 2021, Revised: December 2, 2021, Accepted: December 9, 2021

First author: Hye Ran Kwack, kwack621@snue.ac.kr, (D) https://orcid.org/0000-0003-0193-2056

*Corresponding author: Hye Ran Kwack, kwack621@snue.ac.kr, (1D https://orcid.org/0000-0003-0193-2056 
native practice environment and secure practice tools (Bang, 2017).

A number of studies have emphasized the need for practice tools (Hwang et al., 2017). For elementary school students in the specific operational stage, effective learning materials are of great importance. In particular, for horticultural activities, where the stimulation of the five senses is important, active learning can occur by using an effective horticultural tool for manipulation, observation and cultivating sensory abilities (Lee, 2010). Various plant kits that have already been developed mainly in advanced horticultural countries are known to revitalize horticultural education and double the educational interaction (Chung and Kwack, 2009; Lee, 2010). In particular, as paradigm change, technology development, and development of various tools are required in the educational field to enable classes in a contactless situation under COVID-19 situation, it is possible to increase the possibility of classes due to the simplification of material preparation and the convenience of delivery (Chung and Kwack, 2009; Lee, 2021).

Therefore, in order to enhance the various educational effects of horticultural activities and to enable horticultural education in a non-face-to-face classroom environment, a more realistic solution is needed. With that judgement, this study intended to develop the horticultural education kit directly in cooperation with a professional manufacturer (www.ebable.co.kr). The horticultural kit developed at this time is developed in consideration of educational methods such as character storytelling (Woo, 2020), usability in the curriculum (Chae, 2018), and an assembly form that is easy to deliver for contactless teaching environment. After applying this in the school field, the educational effect and utilization were studied.

\section{Research Methods}

\section{Development of Horticultural Kits for Education}

Among a number of horticultural education activities, we selected a bean germination activity that is included in the elementary science curriculum in 2015 and is frequently performed as a school horticulture activity, and devised a horticultural kit for germination. Recently, in the field of education, interest in qualitative educational content is increasing. Among them, storytelling (Kim, 2021) and character storytelling that uses characters as one of the measures (Woo, 2020) are of continuous interest and are being used as an effective educational method for evoking, and in particular, it is used as an effective method for design product development (Byun, 2018). Therefore, in this study, a horticultural kit with various differentiations such as storytelling activity sheet, characterization, hydroponics type and prefab type was developed in consideration of these measures and other plant observations and the ease of use in a contactless class (Table 1). In particular, storytelling through characters was introduced to horticultural education to highlight the understanding and meaning of activities (Park and Choi, 2014). In addition, acrylic laser cutting was taken in consideration of the convenience of delivery and storage and suitability of individualized classes for contactless classes. Accordingly, the kit components consisted of three types of kit main frame (characterization), storytelling activity sheet, and user manual (manual) as shown in Table 2. At this time, the kit main frame was inserted into a general plastic cup and devised in the form of hydroponics and it was developed into acrylic laser cutting method in cooperation with a professional development company (www.ebable.co.kr) for the development of plant teaching aids.

Table 1. Differentiation of horticultural kits developed through this study

\begin{tabular}{cl}
\hline Composition & \multicolumn{1}{c}{ Description } \\
\hline Characterization & $\begin{array}{l}\text { Introduction of bean characterization of the kit main frame to increase the meaning and understanding of kit } \\
\text { activities }\end{array}$ \\
Assembly type & $\begin{array}{l}\text { Development of an acrylic laser-cutting assembly kit for hydroponics, delivery convenience for contactless classes, } \\
\text { suitability for individualized classes, and delivery and storage convenience }\end{array}$ \\
Storyline & Story line composition for the development of fairy tale stories related to horticultural activities \\
\hline
\end{tabular}


Table 2. Composition of the horticultural kit developed through this study

\begin{tabular}{ccl}
\hline Composition & Usage & \multicolumn{1}{c}{ Description } \\
\hline $\begin{array}{c}\text { Character germination kit } \\
\text { main frame }\end{array}$ & Germination main frame and seed holder & $\begin{array}{l}\text { Characterized main frame for germination and a seed holder } \\
\text { that is inserted into the cup in the form of a holder }\end{array}$ \\
Storyline board & Storytelling related to germination & Storyboard with storylines 1, 2 and 3 related to germination \\
$\begin{array}{c}\text { Assembly instructions } \\
\text { (manual) }\end{array}$ & $\begin{array}{c}\text { Assembly of germination kit and } \\
\text { description of parts utilization }\end{array}$ & $\begin{array}{l}\text { Assembly instructions (manual) for understanding germination } \\
\text { kit assembly and use }\end{array}$ \\
\hline
\end{tabular}

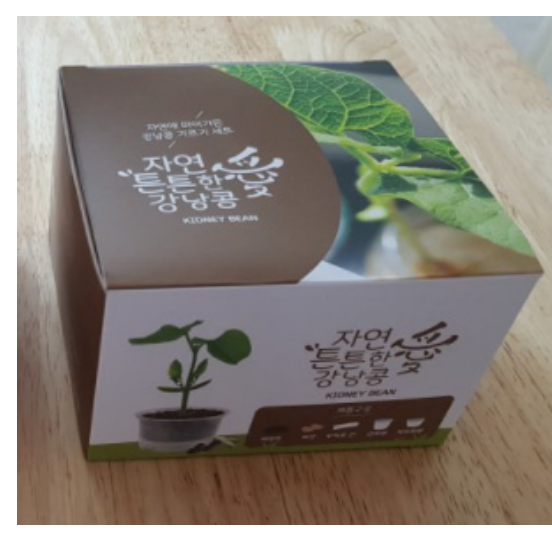

Commercially available kidney bean germination kit (sold at Daiso)

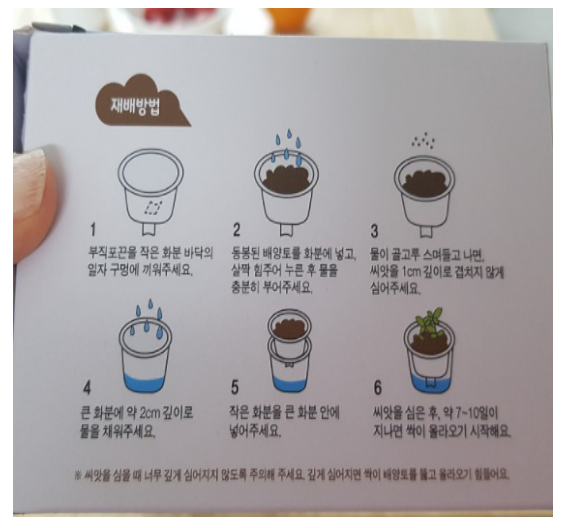

Germination kit instruction manual

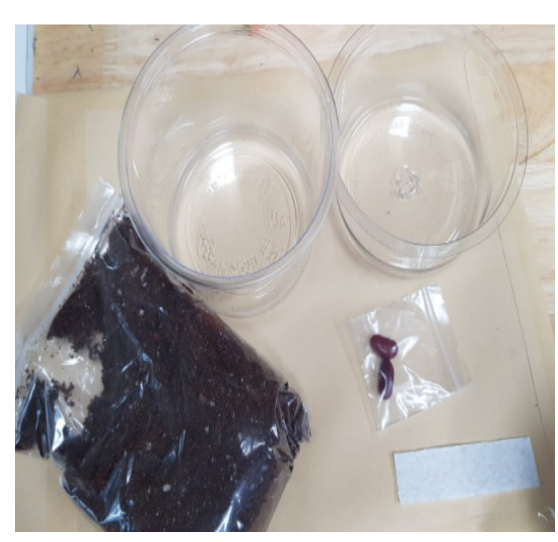

Germination cup, culture soil, kidney bean, and wick

Fig. 1. Commercial germination kit composition (available at Daiso).

\section{Development of Programs Using Horticultural Kits}

It is also specified in the elementary science curriculum (Chae, 2018), and the bean sprouting activity was selected as a frequently performed horticultural education topic. Thus, an educational program was developed for this purpose. At this time, two germination kits are used: one is a general germination kit, a kidney bean germination kit (Fig. 1) sold at Daiso, which includes transparent cups, beans, culture soil and wicks and the other is the horticultural germination kit developed in this study (Fig. 2) and we developed a program to utilize them (Table 3). In each program, the commercially available germination kit program was conducted using the included kit components, and the horticulture education germination kit program had the kit components composed of acrylic assembly parts to be assembled and completed by students themselves according to the manual. Character storytelling was continuously performed during class and observation period using storytelling activity sheets, and plant roots, stems, and leaves were observed simultaneously through hydroponics during the observation period (Table 3).

\section{Program Target Participants}

After constructing two types of germination activity programs using two kit types, the germination program was applied to 50 students in two classes in the fourth grade of an elementary school in Seoul, three times each. As a result of the questionnaire survey after application of the program, 36 of the total 40 students who participated in the class were analyzed, excluding those who participated in the class repeatedly.

\section{Program Application}

The program was divided into one class for the general germination kit class as the comparison group and one class for the horticultural education kit class as the experimental group. The class stage consisted of a preliminary questionnaire, the 1st and 2nd classes, observation log writing 


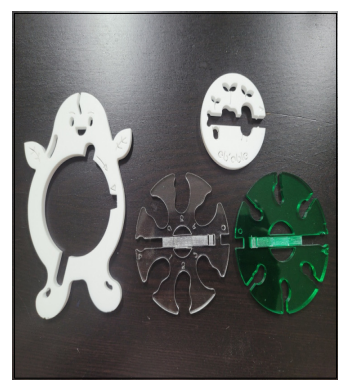

Germination kit components: germination stand, seed holder

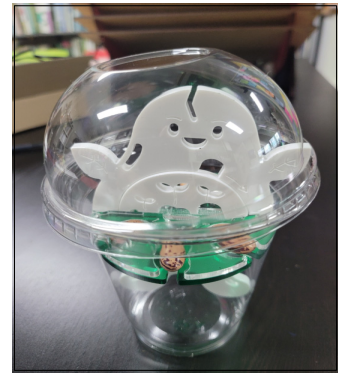

Complete with the kit in a cup: complete the germination kit by putting it in a germination cup filled with water.

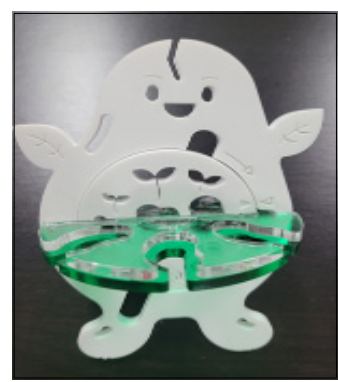

Assembled germination kit: the germination stand and the seed holder can be inserted

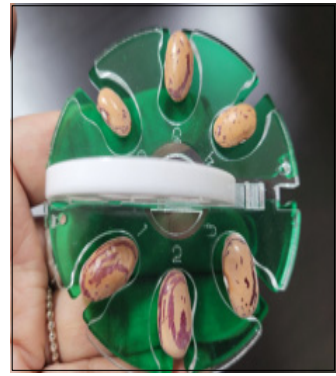

Beans planted in the cradle: it is composed in the form of placing beans on a bean-shaped holder.

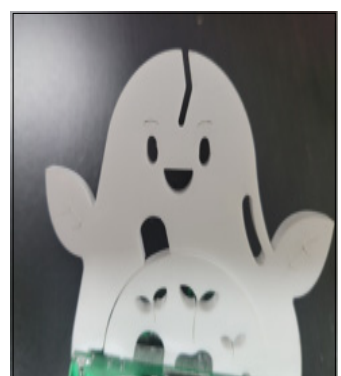

Germination kit characterization (personification): bean shape characterization of kits for educational interest and effects, such as storytelling

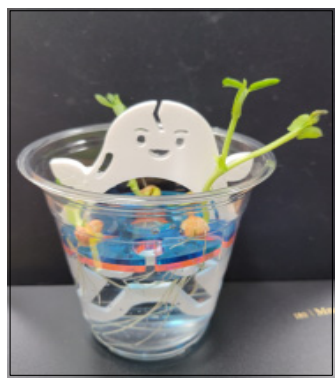

Soybeans germinated on the stand

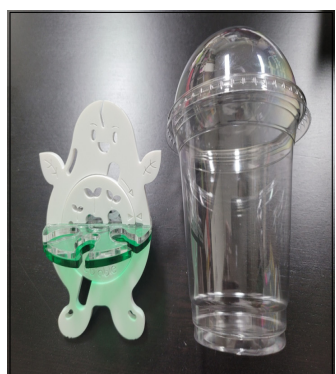

Germination kit and germination cup: composed of germination kit and transparent cup for observation

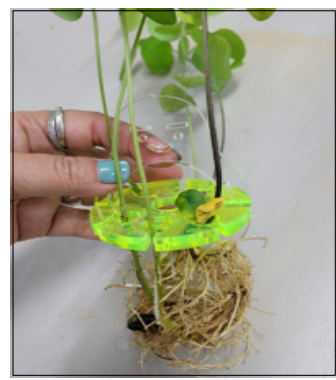

Roots growing on a stand

Fig. 2. Composition and application of the horticulture education kit.

Table 3. Two types of germination education programs

\begin{tabular}{cccl}
\hline Types of program & Times & Kit composition & \multicolumn{1}{c}{ Intention of program } \\
\hline $\begin{array}{c}\text { Commercially available general } \\
\text { germination kit application program }\end{array}$ & 3 & $\begin{array}{c}\text { Disposable cup, culture soil, } \\
\text { kidney beans, wick }\end{array}$ & $\begin{array}{l}\text { Use commercially available germination kits to explore } \\
\text { scientific knowledge related to germination. }\end{array}$ \\
$\begin{array}{c}\text { Program using germination kit for } \\
\text { horticultural education }\end{array}$ & 3 & $\begin{array}{c}\text { Germination main frame, seed } \\
\text { holder, storyboard, manual }\end{array}$ & $\begin{array}{l}\text { Use the developed germination kit to enhance scientific } \\
\text { knowledge and emotional interest about germination through } \\
\text { kit assembly, character storytelling, and plant observation. }\end{array}$ \\
\hline
\end{tabular}

(6 times in 2 weeks), the 3rd class, and post-survey (Table 4).

\section{Survey Content and Analysis}

\section{Survey content}

For the effect of class, the questionnaire and observation $\log$ should be analyzed. In the questionnaire, horticultural class satisfaction and plant interest were compared and analyzed before and after class in two classes of the same grade. As a test tool, the questionnaire on satisfaction and attitude change of the Korea Foundation for Science and
Creativity (www.kofac.re.kr) was reconstructed and used for this study, and the content and reliability of the questions are shown in Table 5. The plant interest level was used by reconstructing the horticultural plant interest level question (Bae and Park, 2018), and the item contents and reliability are shown in Table 6 . All items were constructed on a 5-point Likert scale.

After the first class, an observation log was prepared to investigate the change in the attitudes of the students regarding the germination process. At this time, the contents and format of the observation $\log$ are shown in Table 7 , 
Table 4. Description of program application

\begin{tabular}{|c|c|c|}
\hline Step & Process & Class content \\
\hline \multicolumn{2}{|c|}{ Preliminary questionnaire } & Satisfaction with horticulture class, interest in plants \\
\hline \multirow{2}{*}{ 1st class } & Comparison & $\begin{array}{l}\text { Using a commercially available germination kit, soybeans are planted in the soil and placed in a suitable } \\
\text { place in the classroom. }\end{array}$ \\
\hline & Experiment & $\begin{array}{l}\text { Assemble the parts of the horticulture education germination kit using the manual, plant the beans in water, } \\
\text { and place them in an appropriate place in the classroom. At this time, learn about the role of each assembly } \\
\text { component presented in the manual and plant growth. }\end{array}$ \\
\hline \multirow[b]{2}{*}{ 2nd class } & Comparison & $\begin{array}{l}\text { Observing kidney beans growing in a commercial germination kit, students learn about the life cycle of } \\
\text { plants and scientific and horticultural knowledge about bean germination. }\end{array}$ \\
\hline & Experiment & $\begin{array}{l}\text { After observing kidney beans growing in a germination kit for horticulture education, and continuing } \\
\text { storytelling learning using characters that visualize the vitality of beans (in this study, story illustration } \\
\text { materials created under the theme of bean growth) were continuously carried out, through which bean growth } \\
\text { can be understood. In addition, students learn about the life cycle of plants and scientific and horticultural } \\
\text { knowledge about bean germination. }\end{array}$ \\
\hline \multirow{2}{*}{$\begin{array}{l}\text { Observation } \\
\quad \log \end{array}$} & Comparison & \multirow{2}{*}{$\begin{array}{l}\text { In the second session of the seed planting activity based on the class content, a germination observation log } \\
\text { is written } 6 \text { times in } 2 \text { weeks after class. }\end{array}$} \\
\hline & Experiment & \\
\hline \multirow[b]{2}{*}{ 3rd class } & Comparison & $\begin{array}{l}\text { Learn the knowledge related to the growth of seeds grown in general germination kits. The contents of the } \\
\text { observation log shared by the paddle and the impressions of the germination observation are announced. }\end{array}$ \\
\hline & Experiment & $\begin{array}{l}\text { Learn the knowledge related to the growth of seeds grown in the horticultural education germination kit. } \\
\text { Present the contents of the observation log shared by the paddle and our impressions about the observation } \\
\text { of germination. }\end{array}$ \\
\hline \multicolumn{2}{|c|}{ Post-survey } & Satisfaction with horticulture class, interest in plants \\
\hline
\end{tabular}

Table 5. Satisfaction with horticulture classes

\begin{tabular}{|c|c|c|c|}
\hline Category & No. & Description & Cronbach's $\alpha$ \\
\hline \multirow{4}{*}{$\begin{array}{l}\text { Demographic } \\
\text { characteristics }\end{array}$} & Class & Classified according to class type & \\
\hline & Gender & Separation of male and female gender & \\
\hline & Degree of interest & Degree of interest in horticultural activities & \\
\hline & Experience & Degree of experience in horticultural activities & \\
\hline \multirow{3}{*}{$\begin{array}{l}\text { Satisfaction with } \\
\text { horticulture classes }\end{array}$} & 1 & Are you interested in horticulture? & \\
\hline & 2 & Do you enjoy horticulture activities? & 0.847 \\
\hline & 3 & Are you an active participant in horticulture activities? & \\
\hline \multirow{3}{*}{$\begin{array}{l}\text { Understanding of } \\
\text { horticulture } \\
\text { activities }\end{array}$} & 4 & Are horticulture activities easier than other classes? & \\
\hline & 5 & Do you think you have a good understanding of horticulture? & 0.641 \\
\hline & 6 & Do you think horticulture activities help you study other subjects? & \\
\hline \multirow{3}{*}{$\begin{array}{l}\text { Horticultural } \\
\text { knowledge } \\
\text { development }\end{array}$} & 7 & Can you explain your horticulture knowledge to others? & \\
\hline & 8 & Do you think horticultural activities can help scientific knowledge? & 0.616 \\
\hline & 9 & Do you know any scientific terms or knowledge related to horticulture? & \\
\hline \multirow{3}{*}{ Interest in horticulture } & 10 & Will horticulture classes make science classes more enjoyable and enjoyable? & \\
\hline & 11 & After taking a horticulture class, are you looking forward to the next horticulture class? & 0.823 \\
\hline & 12 & Can a horticulture class make me more interested in horticulture or plants? & \\
\hline \multirow{3}{*}{$\begin{array}{l}\text { Interest in horticulture } \\
\text { education kit class }\end{array}$} & 13 & Is the horticulture education kit utilization class easier to understand than other classes? & \\
\hline & 14 & Will the horticulture education kit utilization class be more memorable than the usual class? & 0.845 \\
\hline & 15 & Are classes using kits more fun than other classes? & \\
\hline Total & & & 0.917 \\
\hline
\end{tabular}


Table 6. Degree of interest in plants

\begin{tabular}{|c|c|c|c|}
\hline Category & No. & Description & Cronbach's $\alpha$ \\
\hline \multirow{3}{*}{ Empathy ability over life } & 1 & I usually think that life is precious. & \multirow{3}{*}{0.942} \\
\hline & 2 & I believe that plants are equally precious life. & \\
\hline & 3 & I believe that plants should be protected as preciously as animals. & \\
\hline \multirow{3}{*}{ Interest in plants } & 4 & I am usually very interested in plants. & \multirow{3}{*}{0.878} \\
\hline & 5 & I love watching plants grow. & \\
\hline & 6 & I wish there were more plants around me. & \\
\hline \multirow{3}{*}{ Knowledge of plants } & 7 & I am well aware of how plant life arises and grows. & \multirow{3}{*}{0.790} \\
\hline & 8 & I know how to help when a plant has problems (the leaves turn yellow and wither). & \\
\hline & 9 & I can name parts of plants well. & \\
\hline \multirow{3}{*}{ Desire to grow plants } & 10 & I can grow plants well. & \multirow{3}{*}{0.900} \\
\hline & 11 & I want to grow more plants in the future. & \\
\hline & 12 & If there are plants around me, I want to actively grow them. & \\
\hline \multirow{3}{*}{$\begin{array}{c}\text { Psychological } \\
\text { influences from plants }\end{array}$} & 13 & I feel good when I see plants. & \multirow{3}{*}{0.776} \\
\hline & 14 & I often feel calm when I am with plants. & \\
\hline & 15 & When I see the plants around me, I feel curious to know more about them. & \\
\hline Total & & & 0.939 \\
\hline
\end{tabular}

Table 7. Observation log content and format

\begin{tabular}{|c|c|c|}
\hline Category & Description & Format \\
\hline Are there any changes to the beans? & $\begin{array}{l}\text { Changes in soybeans that appear over the number of germination days are } \\
\text { observed and expressed before, during, and after activity. }\end{array}$ & Pictures and text \\
\hline Are you interested in beans? & To quantify interest in beans over time of germination & 5-point Likert scale \\
\hline $\begin{array}{l}\text { How much do you care about } \\
\text { beans? }\end{array}$ & $\begin{array}{l}\text { To quantify the feeling of cherishing beans as the number of germination days } \\
\text { passes. }\end{array}$ & 5-point Likert scale \\
\hline $\begin{array}{l}\text { How do you feel when you see } \\
\text { beans growing? }\end{array}$ & $\begin{array}{l}\text { Let the participants to freely record how they feel while looking at the beans as the } \\
\text { number of germination days goes by. }\end{array}$ & Pictures and text \\
\hline
\end{tabular}

and during the observation period of 2 weeks, it was recorded once every 2-3 days so that a total of 6 observations were made. The type of observation item was a 5-point Likert scale, drawing and writing a sentence depending on the item content. After the observation period, the experimental and non-experimental groups were asked to compare the quantitative and qualitative observations. These results were shared through a padlet so that they could be shared in the post-class, and they were announced during the post-class and linked to the class.

\section{Survey analysis}

The collected questionnaires were analyzed using the statistical program SPSS 25.0 (IBM Co., Armonk, NY, USA). The background variables of the participating students were investigated and the average comparison was made between satisfaction with horticulture activities and understanding of plants for each variable. To investigate the general characteristics of the subjects, frequency analysis was conducted, and students' satisfaction with the program and plant interest were analyzed through t-test and analysis of variance. The reliability of the questionnaire was calculated by Cronbach's $\alpha$ value, and statistical significance was used at the 0.05 level. The observation log is posted on the Padlet between the 1st and 2nd classes, and the changes in the contents correspond to the t-test for the quantitative questionnaire and the educational goal of Bloom (Borich, 2000) for the qualitative questionnaire. The t-test was performed after coding by classifying the language corresponding to the cognitive, definitional, and physical domains domain (Table 8). 


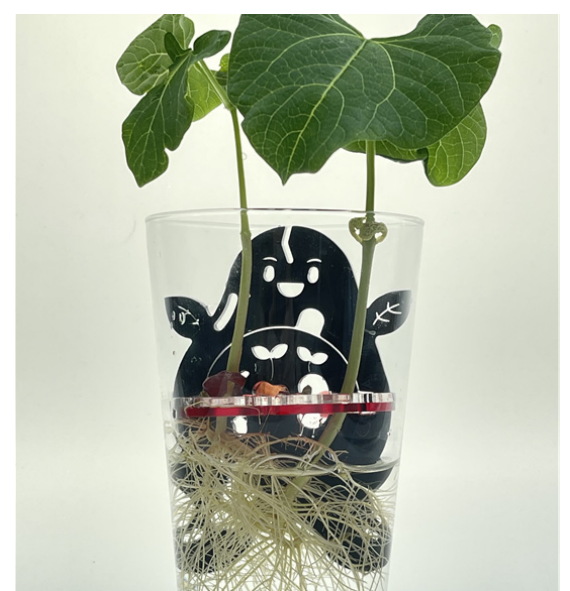

Characterized germination kit main frame

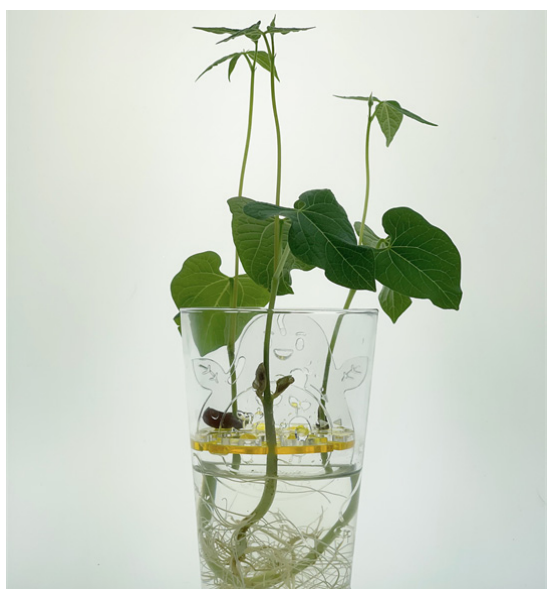

Hydroponics use

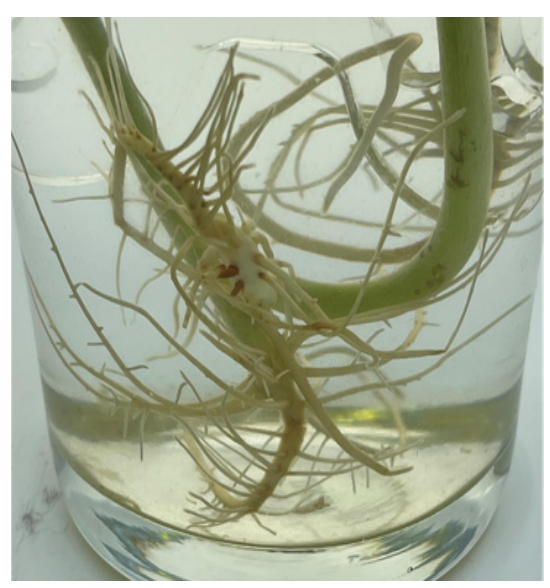

Ease of root observation

Fig. 3. Horticulture education kit for character storytelling and easy root observation.

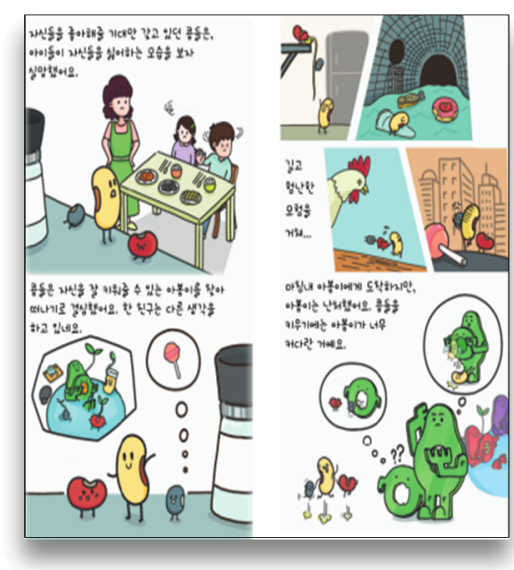

Story 1. Birth of Germination Kit: Beans go on an adventure to avoid children who hate beans.

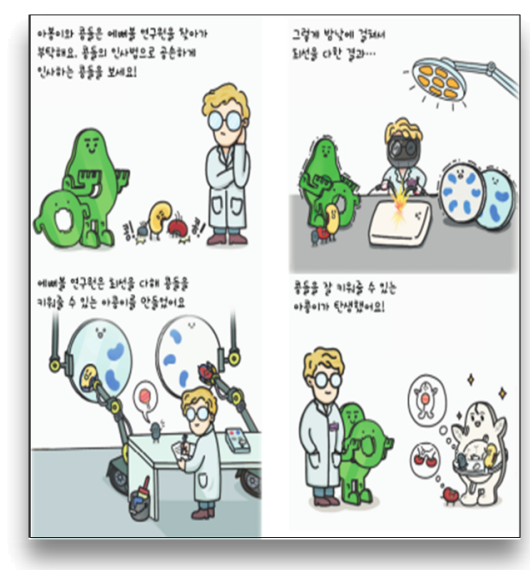

Story 2 . Soybeans are invented by asking an expert to develop a germination kit that children can easily grow beans.

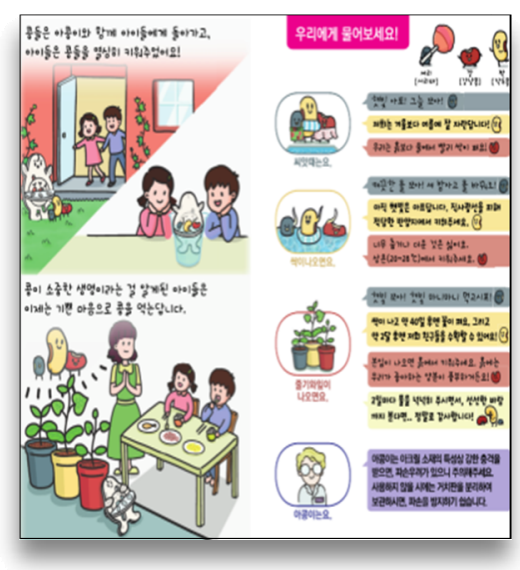

Story 3 . Soybeans are invented by asking a professional to develop a germination kit that allows children to easily grow beans.

Fig. 4. Activity sheet for storytelling.

\section{Results and Discussion}

\section{Development of Horticultural Kit for Education}

The composition of the horticultural education kit developed through this study is a $<$ bundle type $>$ that includes all of the kit main frame (Figs. 2 and 3), storytelling activity sheet (Fig. 4), and parts assembly manual (Fig. 5). It was produced in cooperation with a professional company (www.ebable.co.kr). The composition of the germination main frame is a method in which culture soil is placed in a general plastic cup of a commercially available germi- nation kit (Fig. 1) for classes, which was differentiated by the main frame configuration as shown in Figs 2 and 3 in this study. The germination main frame is a finished product that children assemble and complete by themselves, which is differentiated from the existing finished product type kit, and consists of a seed holder and a germination rod that can be inserted. At this time, the germination stand includes a seed holder, and characterization was designed as one of the approaches to use storytelling in education (Figs. 2 and 3). In recent years, storytelling has been widely used as a new educational paradigm that viv- 

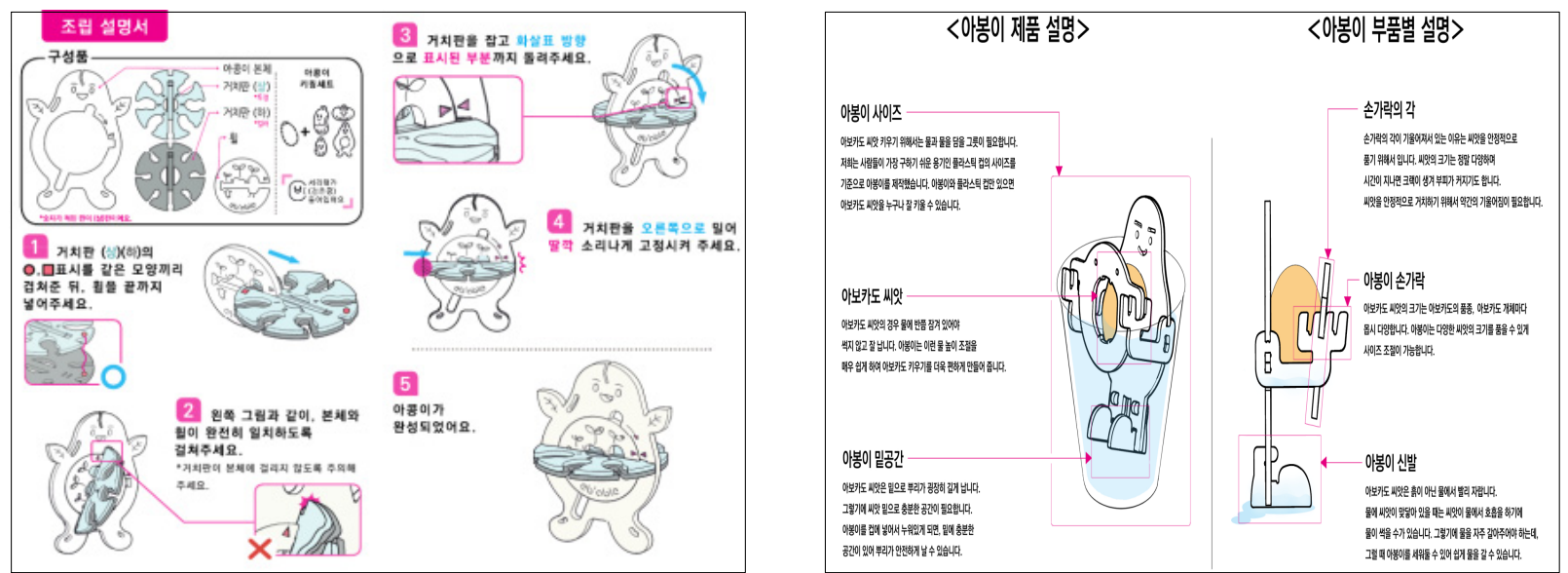

Fig. 5. Assembly of horticulture kit for education.

Table 8. Bloom's classification of learning goals

\begin{tabular}{|c|c|c|}
\hline Category & Description & Format \\
\hline Cognitive domain & Intellectual ability and functional development & $\begin{array}{l}\text { Knowledge, understanding, application, analysis synthesis, } \\
\text { evaluation }\end{array}$ \\
\hline Affective domain & Developing attitudes, beliefs, and values & $\begin{array}{l}\text { Acceptance, responsiveness, valuation, organization, } \\
\text { personalization }\end{array}$ \\
\hline Psychomotor domain & Physical activity and functional development & Imitation, manipulation, accuracy, association, mastery \\
\hline
\end{tabular}

idly delivers educational effects and causes memory and empathy (Kim, 2021). In addition, it is said that it will become more effective when using means of expressing emotions (Kim, 2020), however, as one of those methods, the character storytelling industry that uses characters for storytelling is emerging (Woo, 2020). In particular, characters are effective to accompany emotional and sensory sympathy. In this study, in order to introduce such character storytelling to horticultural activities, the germination kit was characterized and a storyline was also produced to maximize emotional and sensory sympathy (Byun, 2013; Kim, 2000; Suh, 2021). The kit main frame is made for hydroponics in a transparent cup so that it is easy to observe stems and roots. This is because most of the commercially available kits are grown in soil, so it is difficult to observe the roots when observing bean germination, so it is difficult to use them in the 2015 school curriculum (Fig. 3) (Chae, 2018).

Fig. 4 is a storytelling activity sheet for germination education created in this study for character storytelling in connection with the character kit. Linking the story 1-2-3 of Fig. 4, which is a creative story, with horticulture activities, children can learn about horticulture activities by doubling motivational factors such as interest, immersion, and empathy. In this regard, it is reported that storytelling- oriented education has a very large immersion effect in children's education recently (Kim, 2020; Suh, 2021). In the 'Study on Plant Kit Development Status and Adequacy of Introduction to Elementary Education' (Chung and Kwack, 2009), children's $<$ Factor of Interest $>$ was found to be the most important plant kit preference. It was found to be a preference and was considered as a condition consistent with the contents of this study.

Fig. 5 is a germination kit manual, and assembly instructions and parts usage instructions are included in the horticulture kit. Most plant kits are composed of a kit container, instructions (manual), and $<$ bundle form $>$ including plant materials (Chung and Kwack, 2009; Lee, 2010).

\section{Survey Analysis Result}

To investigate the educational effect of the horticulture kit, the satisfaction and plant interest of the experimental group and the control group were analyzed by comparing 
Table 9. Satisfaction with horticulture classes

\begin{tabular}{|c|c|c|c|c|c|c|}
\hline Category & Class & No. of people & Average & Standard deviation & $\mathrm{t}$ & $p$ \\
\hline \multirow{2}{*}{ Satisfaction with horticultural classes } & Experiment & 19 & 2.679 & 0.838 & \multirow{2}{*}{2.646} & \multirow{2}{*}{$.018^{*}$} \\
\hline & Comparison & 17 & 1.630 & 0.702 & & \\
\hline \multirow{2}{*}{ Understanding of horticultural activity } & Experiment & 19 & 4.088 & 0.616 & \multirow{2}{*}{3.513} & \multirow{2}{*}{$.003^{* *}$} \\
\hline & Comparison & 17 & 3.556 & 0.661 & & \\
\hline \multirow{2}{*}{ Horticultural knowledge development } & Experiment & 19 & 3.860 & 0.780 & \multirow{2}{*}{2.577} & \multirow{2}{*}{$.020^{*}$} \\
\hline & Comparison & 17 & 3.142 & 0.930 & & \\
\hline \multirow{2}{*}{ Interest in horticulture } & Experiment & 19 & 3.965 & 0.888 & \multirow{2}{*}{3.241} & \multirow{2}{*}{$.005^{* *}$} \\
\hline & Comparison & 17 & 3.202 & 0.805 & & \\
\hline \multirow{2}{*}{ Interest in horticulture kit } & Experiment & 19 & 4.298 & 0.760 & \multirow{2}{*}{3.049} & \multirow{2}{*}{$.006^{* *}$} \\
\hline & Comparison & 17 & 3.593 & 0.807 & & \\
\hline
\end{tabular}

${ }^{*} \mathrm{p}<.05,{ }^{* *} \mathrm{p}<.01$.

Table 10. Interest in plants

\begin{tabular}{|c|c|c|c|c|c|c|}
\hline Category & Class & No. of people & Average & Standard deviation & $\mathrm{t}$ & $p$ \\
\hline \multirow{2}{*}{ Empathy ability over life } & Experiment & 19 & 4.614 & 0.620 & \multirow{2}{*}{2.673} & \multirow{2}{*}{.017} \\
\hline & Comparison & 17 & 3.888 & 0.829 & & \\
\hline \multirow{2}{*}{ Interest in plants } & Experiment & 19 & 3.947 & 1.019 & \multirow{2}{*}{1.354} & \multirow{2}{*}{.194} \\
\hline & Comparison & 17 & 3.535 & 0.856 & & \\
\hline \multirow{2}{*}{ Knowledge about plants } & Experiment & 19 & 3.965 & 0.930 & \multirow{2}{*}{2.001} & \multirow{2}{*}{.063} \\
\hline & Comparison & 17 & 3.312 & 0.981 & & \\
\hline \multirow{2}{*}{ Desire to grow plants } & Experiment & 19 & 4.140 & 0.963 & \multirow{2}{*}{2.704} & \multirow{2}{*}{$.016^{*}$} \\
\hline & Comparison & 17 & 3.397 & 0.981 & & \\
\hline \multirow{2}{*}{ Psychological effects on plants } & Experiment & 19 & 4.263 & 0.829 & \multirow{2}{*}{3.175} & \multirow{2}{*}{$.006^{* *}$} \\
\hline & Comparison & 17 & 3.418 & 0.848 & & \\
\hline
\end{tabular}

${ }^{*} p<.05,{ }^{* *} p<.01$.

them before and after the class (Tables 9 and 10). In the case of horticultural class satisfaction, the value of the experimental group was high in all areas of satisfaction, understanding, knowledge development, and interest, and the difference with the non-group was also statistically significant $(p<.05)$ (Table 9). In particular, the significance of understanding of horticulture activities $(p=.003)$ and interest in horticulture classes $(p=.006)$ was high. In the case of plant interest, the value of the experimental group was also high in most areas of empathy for life, plant interest, plant knowledge, desire to grow plants, and psychological effects on plants, and the difference with the non-group was also statistically significant $(p<.05)$ (Table 10). In particular, the psychological effect on plants ( $p=$ .006) was statistically significant, indicating that the use of a horticultural kit was effective in increasing interest in plants (Table 10). This is because, compared to commercially available kits, the horticulture education kit for germination has a higher educational effect such as character storytelling, can be made directly through assembly, and can be observed more accurately and easily. It was considered that this was due to differences in the addition of devices. This was considered as a creative educational method that can double the educational effect of existing horticultural activities (Byun, 2013; Park and Choi, 2014; Suh, 2021) (Table 9).

\section{Analysis Result of Activity Sheet}

After the first class, the observation $\log$ of the experimental and non-experimental groups was comparatively analyzed in order to investigate the qualitative 
Table 11. Analysis of sentence expression for bean germination observation

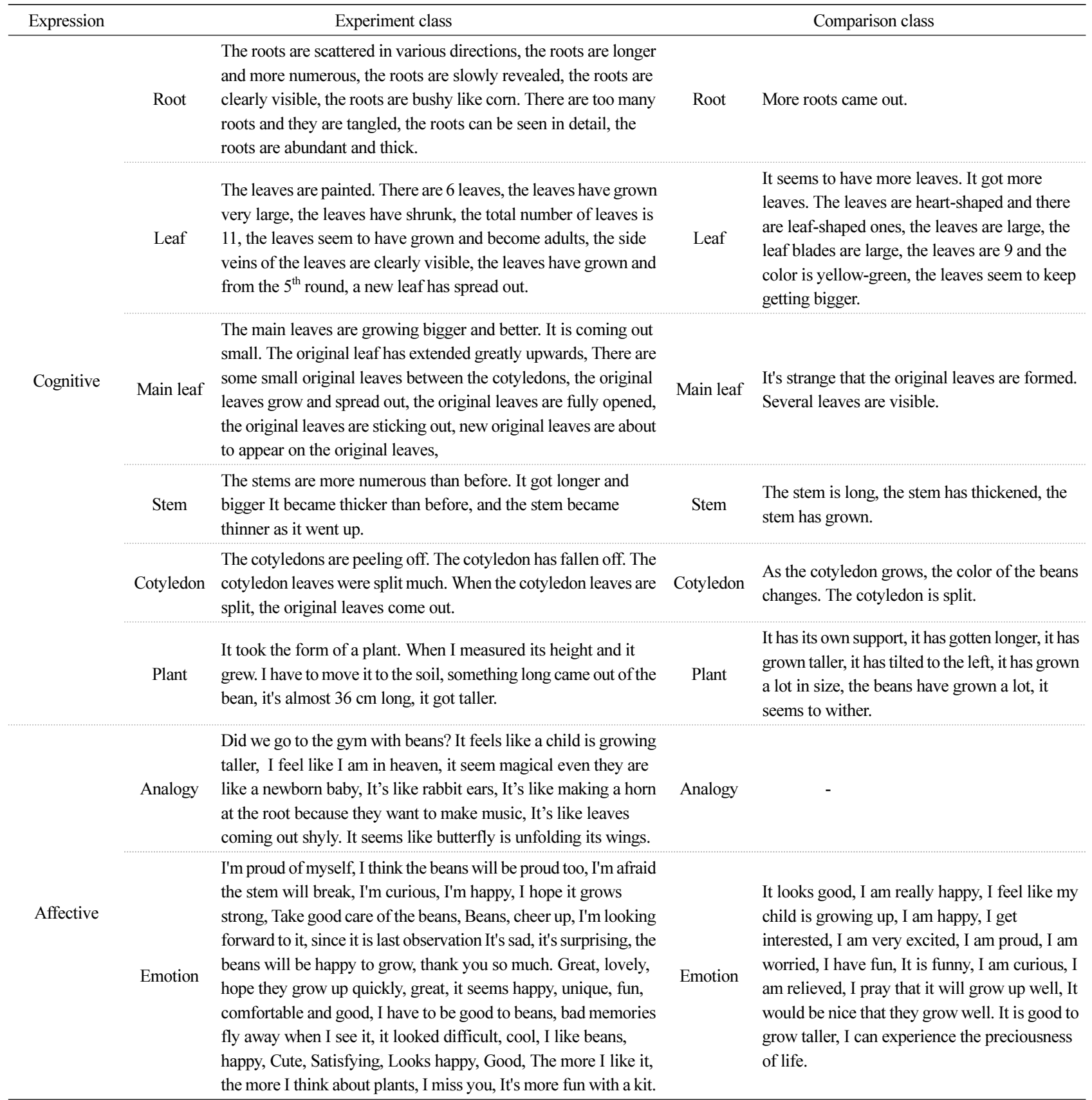

change of attitude of the students regarding the germination progress. Except for the 1st-3rd germination observation log, which showed little change in germination, the 4th-6th time (between 1 and 2 weeks after the start of the experiment) observation log where visible changes were possible were analyzed as targets. Table 11 shows the results of sentence expression analysis for 'What changes are there in beans?' and 'How do you feel when you see growing beans?' In the cognitive domain, the development of seed germination observation technology was analyzed mainly as intellectual ability and functional development. In the case of the experimental group, due to the nature of the transparent hydroponic cultivation kit, the germination observation of the root, leaf, true leaf, stem, cotyledon, and the whole plant was performed in great detail. It can be seen that, in the elementary education process, important 
Table 12. Analysis of the number of syllables and the number of sentences in the cognitive and affective domains of the observation activity sheet

\begin{tabular}{|c|c|c|c|c|c|c|c|}
\hline Item & Times & Class & No. of persons & Average & Standard deviation & $\mathrm{t}$ & $p$ \\
\hline \multirow{6}{*}{$\begin{array}{l}\text { No. of } \\
\text { syllables }\end{array}$} & \multirow{2}{*}{4} & Experiment & 19 & 63.89 & 28.649 & \multirow{2}{*}{4.132} & \multirow{2}{*}{$.001^{\prime}$} \\
\hline & & Comparison & 13 & 25.92 & 14.139 & & \\
\hline & \multirow{2}{*}{5} & Experiment & 19 & 62.11 & 25.749 & \multirow{2}{*}{5.895} & \multirow{2}{*}{$.000^{*}$} \\
\hline & & Comparison & 13 & 19.23 & 12.872 & & \\
\hline & \multirow{2}{*}{6} & Experiment & 19 & 60.42 & 34.654 & \multirow{2}{*}{4.087} & \multirow{2}{*}{$.002^{*}$} \\
\hline & & Comparison & 13 & 20.85 & 19.170 & & \\
\hline \multirow{6}{*}{ Cognitive } & \multirow{2}{*}{4} & Experiment & 19 & 2.05 & 1.026 & \multirow{2}{*}{5.196} & \multirow{2}{*}{$.000^{*}$} \\
\hline & & Comparison & 13 & 0.38 & 0.650 & & \\
\hline & \multirow{2}{*}{5} & Experiment & 19 & 2.53 & 1.307 & \multirow{2}{*}{4.721} & \multirow{2}{*}{$.000^{*}$} \\
\hline & & Comparison & 13 & 0.69 & 0.480 & & \\
\hline & \multirow{2}{*}{6} & Experiment & 19 & 3.47 & 6.753 & \multirow{2}{*}{1.477} & \multirow{2}{*}{.168} \\
\hline & & Comparison & 13 & 0.69 & 1.251 & & \\
\hline \multirow{6}{*}{ Affective } & \multirow{2}{*}{4} & Experiment & 19 & 2.32 & 1.376 & \multirow{2}{*}{3.426} & \multirow{2}{*}{$.005^{* *}$} \\
\hline & & Comparison & 13 & 1.08 & 0.494 & & \\
\hline & \multirow{2}{*}{5} & Experiment & 19 & 1.89 & 1.288 & \multirow{2}{*}{1.047} & \multirow{2}{*}{.316} \\
\hline & & Comparison & 13 & 1.23 & 1.013 & & \\
\hline & \multirow{2}{*}{6} & Experiment & 19 & 1.95 & 1.224 & \multirow{2}{*}{2.592} & \multirow{2}{*}{$.024^{*}$} \\
\hline & & Comparison & 13 & 0.85 & 0.801 & & \\
\hline
\end{tabular}

root observation was characteristically performed, and other germination processes were also observed in detail (Chae, 2018). On the other hand, in the case of the control group using the germination kit for planting in general soil, germination observation of all plant organs was rather superficial, and in particular, due to the nature of planting in soil, root observation was not performed at all (Table 11). In the affective domain expression, the experimental group made it possible for children to express various expressions, empathy, and personification of the roots, cotyledons, and main leaves. In particular, expressions such as 'it seems like a child is growing', 'it seems to be embracing a baby', 'it seems to have rabbit ears', and 'the leaves come out shyly' are the educational characteristics of the germination kit, such as characterization and storytelling. It was found that this had a great influence (Byun, 2013) (Table 11).

In order to quantify the difference in sentence expression quality for the questions like 'What are the changes in beans?' and 'How do you feel when you see growing beans?', we quantified the number of syllables in a sentence as a method of measuring the amount of speech in the lexical analysis method (Chung, 2014) In addition, after quantifying the number of sentences expressing cognitive and affective domains according to Bloom's educational goals (Borich, 2000), the difference in change between the experimental and comparison groups was analyzed (Table 12). At this time, the 4 th $\sim 6$ th observation activity sheets were also analyzed (Table 12). As a result of the analysis, the experimental group had high results in the number of syllables, sentences in all the cognitive and affective domains, and the statistical validity of the difference from the comparison group was very significant $(p<.05)$ (Table 12). In particular, the difference in the number of syllables was very clear, indicating that the emotional expression level between the groups was very different (Table 12).

In addition, the experimental group was superior in both the level of 'interest in plants' and the level of 'caring for plants', which were asked to answer with the Likert scale in the observation log, and all differences against the 
Table 13. Analysis of observational activity sheets for 'interest in plants' and 'affection to care for plants'

\begin{tabular}{|c|c|c|c|c|c|c|c|}
\hline Item & Times & Category & No. of people & Average & Standard deviation & $\mathrm{t}$ & $p$ \\
\hline \multirow{6}{*}{$\begin{array}{l}\text { Interest in } \\
\text { plants }\end{array}$} & \multirow{2}{*}{4} & Experiment & 19 & 4.47 & 0.905 & \multirow{2}{*}{2.739} & \multirow{2}{*}{$.018^{*}$} \\
\hline & & Comparison & 13 & 3.62 & 0.650 & & \\
\hline & \multirow{2}{*}{5} & Experiment & 19 & 4.58 & 0.692 & \multirow{2}{*}{5.196} & \multirow{2}{*}{$.000^{* * *}$} \\
\hline & & Comparison & 13 & 3.62 & 0.650 & & \\
\hline & \multirow{2}{*}{6} & Experiment & 19 & 4.74 & 0.562 & \multirow{2}{*}{3.860} & \multirow{2}{*}{$.002^{* *}$} \\
\hline & & Comparison & 13 & 3.69 & 0.630 & & \\
\hline \multirow{6}{*}{$\begin{array}{l}\text { Affection to } \\
\text { care for } \\
\text { plants }\end{array}$} & \multirow{2}{*}{4} & Experiment & 19 & 4.68 & 0.478 & \multirow{2}{*}{6.121} & \multirow{2}{*}{$.000^{* * *}$} \\
\hline & & Comparison & 13 & 3.62 & 0.650 & & \\
\hline & \multirow{2}{*}{5} & Experiment & 19 & 4.79 & 0.419 & \multirow{2}{*}{4.416} & \multirow{2}{*}{$.001^{* *}$} \\
\hline & & Comparison & 13 & 3.62 & 0.650 & & \\
\hline & \multirow{2}{*}{6} & Experiment & 19 & 4.84 & 0.575 & \multirow{2}{*}{10.119} & \multirow{2}{*}{$.000^{* * *}$} \\
\hline & & Comparison & 13 & 3.69 & 0.630 & & \\
\hline
\end{tabular}

${ }^{*} p<.05,{ }^{* *} p<.01,{ }^{* * *} p<.001$.

comparison group were effective $(p<.05)$ (Table 13). Through this difference, besides the educational characteristics of germination observation activity as a horticultural activity, the educational effect and importance of the various educational intentions and devices of the horticultural kit developed in this study can be assessed together with other previous studies. Therefore, it was considered as a reference point in future related studies (Lee and Chung, 2016; Hwang et al., 2017).

Table 13. Analysis of observational activity sheets for 'interest in plants' and 'affection to care for plants'

\section{Conclusion}

This study newly developed a horticultural kit for germination that added storytelling, characterization, and manual assembly for effective horticultural education, and investigated the effectiveness, differentiation and utilization of horticultural education using it. To that end, first, we developed a bean germination education kit. The components consist of three types: the kit main frame (characterization), the storyboard for storytelling, and the assembly instructions (manual). The kit main frame was designed in the form of hydroponics to observe the growth of the whole plant, and the ease of delivery for contactless classes was taken into consideration by making an acrylic assembly through laser cutting.

Second, as a result of applying the horticultural kit use education program (experimental group) and the commercial germination kit program (comparison group), as a quantitative questionnaire, satisfaction with horticultural activity and plant interest were both high in the experimental group, and the difference was also statistically significant $(p<.05)$ In particular, in terms of satisfaction with horticulture activities, the level of understanding of horticulture activities and interest in horticulture classes were found to be high, and the interest in horticulture kits was also significantly higher in the experimental group. In terms of interest in plant, it was found that the difference in the psychological effect on plants was very significant compared to other items. It was considered that educational devices such as character storytelling had a positive psychological effect on plants. In addition, the educational effect of the experimental group was particularly high in the educational effects of horticultural education, such as the ability to empathize with life and the desire to grow plants, and the statistical difference with the control group was very significant $(p<.05)$.

Third, as a qualitative questionnaire, the observation log of the experimental group and the control group was analyzed by analyzing the number of syllables according to 
the utterance method (Chung, 2014) and the sentences in the cognitive and affective domains according to Bloom's educational goal (Borich, 2000). The number of syllables in the experimental group was significantly higher than in the non-experimental group, and the expressions corresponding to the cognitive and affective domains as the sentence expression contents were also significantly higher in the experimental group, and the statistical difference from the non-experimental group was also very significant ( $p$ $<.05)$. In the case of the experimental group, observational texts specifically expressing various plant organs were mainly written in the cognitive domain, and root observation was also done in detail due to the characteristics of hydroponics. It was expressed in an interesting way with a unique description, and the contents of empathy that personified the growth of beans as an emotional expression were very diverse.

On the other hand, the comparison group did not have many expressions and emotional expressions were not revealed in various ways. The results of this study show that children's horticulture kits are needed to effectively teach horticulture in the contactless era, especially based on characterization, storytelling activity sheets, self-assembly composition, and suitability to introduce school curriculum. It was important to develop it in earnest as an educational horticulture kit. In addition, these horticultural kits for education increase children's understanding of horticultural activities and interest in horticulture compared to general kits, and through qualitative changes, cognitive development such as scientific knowledge and observational skills about plants, love for plants, and feelings of happiness are expressed, which was found to be superior, so it was considered that the use of a horticultural kit based on a new educational approach such as storytelling of the same character in this study would be very meaningful in future horticulture education.

\section{References}

Bang, K.H. 2017. The study on the structuring of operating organization for agricultural education in elementary · secondary schools. J. Korean Pract. Arts Educ. 23(2):61-81.
Bae, J.H. and Y.J, Park. 2018. The correlation between elementary school students' plant familiarity and perception, attitude of climate change. J. Energy Clim. Chang. Educ. 8(2):79-86 https://doi.org/10.22368/ksecce.2018.8.2.79

Borich, G.D. 2000. Effective Teaching Methods. Upper Saddle River, NJ, USA: Prentice Hall.

Byun, M.J. 2013. Study on the characteristics of narrative structure of storytelling in functional purpose: Research on edutainment and infotainment storytelling. Des. Converg. Stud. 12(3):47-62.

Chae, D.H. 2018. Plant life cycle. Elementary science textbook (4th Grade) (pp. 48-64.). Seoul, Korea: Visang Textbook.

Chung, W.J. and H.R. Kwack. 2009. A study for the development of various kinds of plant kits and suitability for elementary education. J. Korean Pract. Arts Educ. 15(4): 105-126.

Chung, S.M. 2014. The word analysis in humanities therapy. Stud. Humanit. 40:735-757

Hwang, H.S., N.W. Park, and S.B. Lee. 2017. An investigation of meaning of pre-service early childhood teacher's experience of teaching material development with creative thinking tools. Korean J. Early Child. Educ. 37(3): 5-28. https://doi.org/10.18023/kjece.2017.37.3.001

Kim, S.J. 2020. A study on storytelling guidance in self-expressive writing education: Focusing on ego-identity establishment and 'event' composition. Donam Lang. Lit. 38:389-417.

Kim, J.Y. 2021. Effects of a creative dance class applied with storytelling upon self-expression ability, empathy ability and peer relationship of middle school students. Korean J. Sport Sci. 30(5):739-752. https://doi.org/10. 35159/kjss.2021.10.30.5.739

Lee, J.H. 2010. A study for development of gardening vessel for elementary plant education. Master's thesis, Seoul National University of Education, Seoul, Korea.

Lee, Y.J. and M.K. Chung. 2016. Analysis of terminology of educational materials and technique of 'environment and sharing of life supplies making' chapter and proposition of standardized terminology. J. Korean Pract. Arts Educ. 22(1):205-220.

Lee, D.H. 2021. Media ecological exploration of digital classrooms in the era of COVID-19: A focus on the remote classroom environment mediated by Zoom. Korean 
J. Broadcast. Telecommun. Stud. 35(2):98-130.

Park, H.S. 2005. Study of effective cultivation, fostering training guidance in elementary school: focusing on Jeju area. Master's thesis, Jeju National University, Jeju, Korea.

Park, H.J. and W.J. Choi. 2014. A study on the character design of the asian university sports federation based on semantic visual approach. J. Basic Des. Art. 15(5): 45-68.

Suh, H.K. 2021. A study on the educational plan first per- son storytelling of realistic content. J. Korea Soc. Comput. Inf. 25(11):67-74. https://doi.org/10.9708/jksci.2020.25. 11.067

Woo, J.I. 2020. A study on the social imagination of character storytelling: Focusing on 'Pengsoo' characters. Cartoon Animat. Stud. 61:255-287. http://dx.doi.org/10. 7230/KOSCAS.2020.61.255

$\mathrm{http}: / /$ www.ebable.co.kr

http://www.kofac.re.kr 